
allemande

46-2 | 2014

Intellectuels et politique en Allemagne

\title{
Elisa KLAPHECK, Margarete Susman und ihr jüdischer Beitrag zur politischen Philosophie
}

Berlin, Hentrich \& Hentrich, 2014

Dominique Bourel

\section{(2) OpenEdition}

Journals

Édition électronique

URL : https://journals.openedition.org/allemagne/1710

DOI : 10.4000/allemagne. 1710

ISSN : 2605-7913

Éditeur

Société d'études allemandes

Édition imprimée

Date de publication : 30 décembre 2014

Pagination : 511

ISSN : 0035-0974

Référence électronique

Dominique Bourel, «Elisa KLAPHECK, Margarete Susman und ihr jüdischer Beitrag zur politischen

Philosophie », Revue d'Allemagne et des pays de langue allemande [En ligne], 46-2 | 2014, mis en ligne le 29 juillet 2019, consulté le 27 mai 2021. URL : http://journals.openedition.org/allemagne/1710 ; DOI https://doi.org/10.4000/allemagne. 1710 
Elisa KLAPHECK, Margarete Susman und ihr jüdischer Beitrag zur politischen Philosophie, Berlin, Hentrich \& Hentrich, 2014, 408 p. (dont index).

Voici un ouvrage remarquable sur une figure qui ne l'est pas moins, Margarete Susman, femme, juive, allemande et philosophe! Elle est née en 1872 à Hambourg et décède en 1966 à Zurich où elle passe une partie de son enfance, de son adolescence, et de sa vie après 1933: ces dates suffisent à indiquer un destin tragique. Issue d'une famille de la bourgeoisie libérale juive, elle fréquente à Berlin le séminaire de Simmel où elle rencontre entre autres Martin Buber, Ernst Bloch et Bernhard Groethuysen et étudie, après le décès de son père qui ne voulait pas qu'elle fít des études supérieures, la peinture à Düsseldorf et à Paris avant de se fixer à Francfort où elle fut un des grands auteurs de la Frankfurter Zeitung. Elle publie aussi, sous la houlette de Simmel, une traduction de I'Introduction à la métaphysique de Bergson (léna, Eugen Diedrichs, 1909). Mariée, un temps, à l'historien de l'art Eduard von Bendemann, mais ayant refusé de se faire baptiser, elle continue son apprentissage à Munich et à Berlin (où elle habite quelques années) puis commence à publier des poèmes remarqués. De retour en Suisse à Rüschlikon près de Zurich en 1912, elle publie alors dans la célèbre NZZ et les Basler Nachrichten. Elle est la seule femme à participer à la légendaire anthologie Vom Judentum publiée à Prague en 1913 par la galaxie Buber avec lequel elle est très liée ainsi qu'avec tout le milieu de la renaissance juive qui règne à l'époque sur le judaïsme germanophone. Elle parvient à émigrer en Suisse en 1933 où, très proche du groupe du socialiste religieux Leonhard Ragaz, elle continuera une méditation intense sur le peuple juif, et dictera (elle est morte aveugle) une des plus belles autobiographies publiées par une femme juive allemande, Ich habe viele Leben gelebt (Stuttgart, DVA, 1964), après avoir reçu un doctorat honoris causa de la faculté de philosophie de la FU de Berlin en 1959. Un autre hommage, Auf gespaltenem Pfad (Darmstadt, 1964), est un des volumes les plus emblématiques de cette culture aujourd'hui disparue avec articles, lettres et souvenirs mêlant les noms de Gershom Scholem, Martin Buber, Paul Celan, Ernst Bloch et tant d'autres. Kafka, Landauer, Cohen mais aussi Rahel Varnhagen, Berta Pappenheim furent l'humus d'une recherche intellectuelle et spirituelle fascinante, d'autant plus qu'elle ne reviendra jamais en Allemagne!

Cette étude, écrite par une fermme rabbin de Francfort-sur-le-Main, présente de manière thématique en sept chapitres, un excursus et une conclusion les grands axes d'une pensée marquée par la passion judéo-allemande et entée sur des figures comme celle de Spinoza, Moses Mendelssohn ainsi que celle des grandes personnalités qu'elle fréquenta comme Franz Rosenzweig, Martin Buber et Leo Baeck qui lui permirent d'avancer une pensée très originale: une analyse des rapports avec le Christianisme, une belle méditation sur la féminité et la recherche d'une torah sécularisée s'inscrivent dans un exil en dehors de la philosophie, parallèle à celui de son existence. Le dialogue entre une tradition idéaliste classique allemande avec une réflexion d'après la Shoah fut le fil conducteur d'une cuvre qui se lit dans des articles, des recensions, des anthologies et quelques cuvres majeures dont Le livre de Job et le destin du peuple juif, paru en 1946 immédiatement après la catastrophe; il est d'ailleurs un des premiers livres à tenter de penser l'impensable. On en possède une belle traduction française (par Cécile et Jacqueline Rastoin, Le Cerf, 2003). Cette monographie, avec des documents et une grosse bibliographie, est très bien informée. Menée d'une plume alerte, elle représente non seulement une contribution importante à la connaissance d'une philosophe juive allemande encore trop méconnue en France mais encore un jalon nouveau sur la voie escarpée de la pensée juive européenne. 